\title{
BUSINESS
}

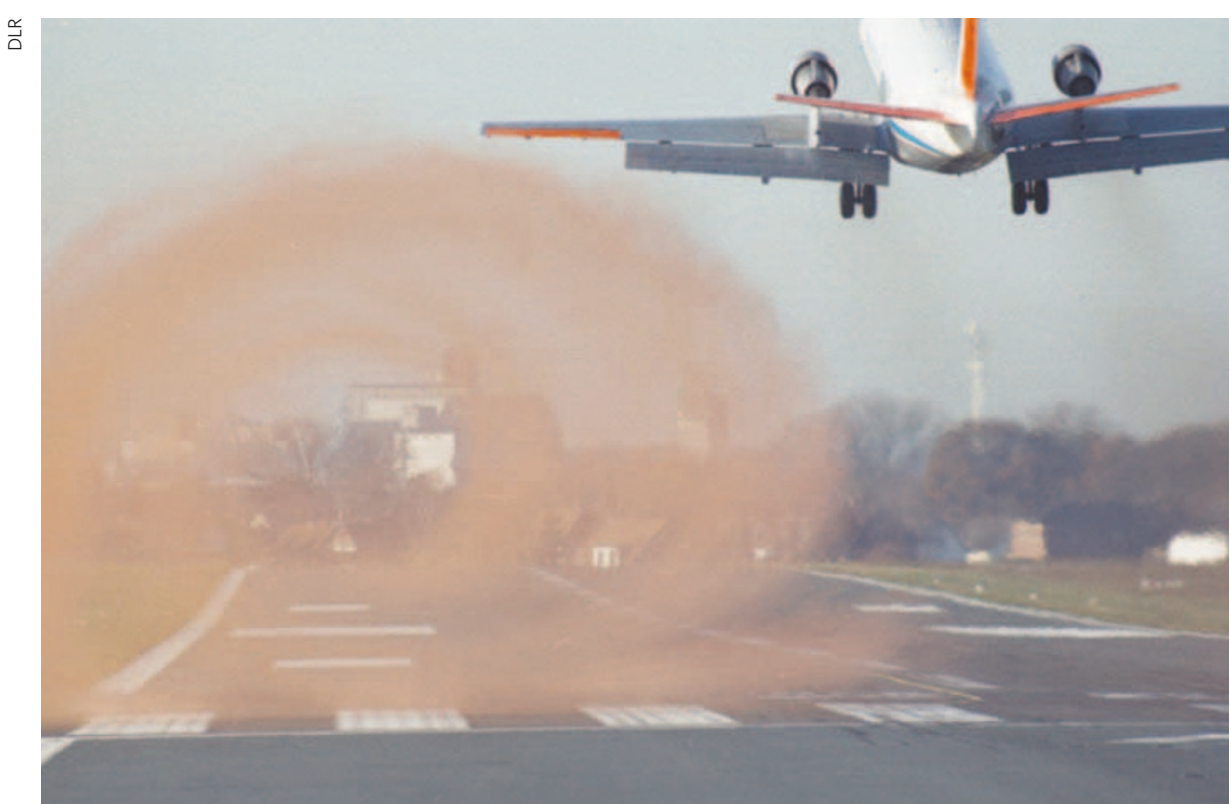

Stay back: wake turbulence could see the Airbus A380 lose take-off and landing slots.

\section{Turbulent times}

\section{The bid by Airbus to challenge the Boeing 747's dominance of the market faces an aerodynamic obstacle. Ned Stafford reports.}

T he success of the world's biggest passenger airliner could hinge on an obscure regulatory decision to be made by the International Civil Aviation Organization (ICAO) later this year.

The European firm Airbus hopes that its A380 can break the Boeing 747's stranglehold on the market for very large airliners. But draft guidelines issued late last year for the European challenger suggest that it could be hampered by safety restrictions.

Over the past decade, the European firm has drawn level with Boeing in terms of overall airliner sales, establishing itself as a rare example of European success in a huge, high-technology industry. However, US industrialists and politicians have bitterly complained that its financing arrangements amount to an unfair subsidy by European governments.

In the airliner market, meanwhile, Boeing has begun to reassert itself, once again surpassing Airbus in total sales. The US manufacturer has rejected costly plans to build a superjumbo akin to the A380, leaving the European manufacturer - and much of Europe's entire aviation industry - relying on the success of the project. But that success is very much in doubt: back in July, Airbus chief executive Gustav Humbert quit over delays to the A380 and other management issues at the company.
If final regulations due this November resemble the preliminary ones, they will add to the project's woes. They will mean that other planes would have to stay farther away from the A380 than from 747s. This could see the A380 lose valuable take-off and landing slots at busy airports, compromising its bid to establish itself in the market.

\section{Bumpy ride}

The problem is turbulent airflow. All aircraft create tornado-like counter-rotating vortices that trail from the tips of the wings as they fly. These can pose a safety risk to other aircraft - especially during take-off and landing. Last year, the ICAO shocked Airbus by suggesting that jets set to take off after A380s should wait for 60 seconds longer than they do behind Boeing $747 \mathrm{~s}$. It also said that planes landing after an A380 should stay back 18 kilometres - about twice the distance they have to hang back from $747 \mathrm{~s}$. And the ICAO suggested more stringent horizontal and vertical spacing requirements for the A380 at cruising altitudes.

Airbus won't comment on the requirements, but Jaakko Hoffren, an aeronautical engineer at the Helsinki University of Technology in Finland says: "My impression is that Airbus had always assumed that the inflight separation requirements for the A380 would be the same as for the Boeing 747."

Increased spacing requirements would defeat the whole rationale for the A380, he asserts. Most major hub airports already have too few take-off and landing slots. If the preliminary requirements get implemented, each A380 flight would mean fewer slots.

Since the preliminary guidelines were issued, Airbus has commissioned the German Aerospace Agency, the DLR, to conduct research that it hopes will prove the A380 is safe at spacing distances closer to, or the same as, those for the Boeing 747. The research used light detection and ranging (LIDAR) - a technique similar to radar, but using light instead of radio waves - to study the vortices created by airliners. It also flew airliners into the wakes of others at cruising altitude, to compare the levels of turbulence.

These studies were "a worldwide first", says David Voskuhl, a spokesman for Airbus. At cruising altitudes "no difference has been found between the two aircraft types", he says. "At low altitude, there is a slightly bigger vortex on the A380, compared with the 747." Voskuhl adds that it is up to the ICAO to decide safe distances for the new aircraft. Boeing and the ICAO declined to comment.

Increased aircraft weight strengthens wake vortices, whereas longer wingspans and increased speed reduce their intensity. The A380 has a maximum take-off weight of 560 tonnes and wingspan of 80 metres, compared with the 747's 397 tonnes and 64 metres.

Current ICAO guidelines divide commercial aircraft into three weight categories: small, medium and heavy. Thomas Gerz, a meteorologist and head of the aerospace agency's wake-vortex project, says that the preliminary guidelines would create a fourth 'super-heavyweight' class, with the A380 as its only member. "There is no reason for this," he says. "The A380 does not justify another weight class." He acknowledges that A380s produce stronger vortices than $747 \mathrm{~s}$, but contends that current ICAO spacing guidelines are "very conservative".

Hoffren says that his calculations suggest "the in-flight separation limits, in time or distance, behind an A380 should be some 10-30\% larger than behind a Boeing 747, for similar hazard levels". He agrees that the ICAO's preliminary A380 guidelines were too stringent - but sees little prospect that the final ones will be the same as those for the 747 .

Hoffren predicts that a surprise compromise could be in store when the ICAO announces its final guidelines. According to the grapevine, Hoffren says, the regulator could deem the A380 safe to fly more closely behind other aircraft - on account of its bulk. That would allow it to leave more space in its wake, while occupying the same time slot as its rival. 